Edwards, and Brian Gibbons, for their cooperation and support.

I Stephens SDG, Barcham LJ, Corcoran AL, Parsons N. Evaluation of an auditory rehabilitation scheme. In: Taylor IG, Markides A, eds. Disorders of auditory function III. London: Academic Press, 1976:265-73.

2 Brooks DN. The use of hearing aids by the hearing impaired. In: Stephen SDG, ed. Disorders of auditory function II. London: Academic Press, SDG, ed. D

Davis A. The epidemiology of hearing disorders. In: Hinchcliffe R, ed. Hearing and balance in the elderly. Edinburgh: Churchill Livingstone, 1983:1-43.
+ Stephens SDG. Lewis PA, Charny SC, Farrow SC, Francis M. Characteristics of self-reported hearing problems in a community surves. Audiology (in press

5 Davis AC. Epidemiology of hearing disorders. In: Stephens D, ed. Scot Brown's otolaryngologv. 5th ed. Vol 2. London: Butterworth, 1987:90-126.

6 Stephens SDG, Meredith R, Callaghan DE, Hogan S, Rayment A. Early intervention and rehabilitation: factors influencing outcome. Actu Otolaryngol intervention and re

7 Davies JE. John DG, Stephens SDG. Intermediate hearing tests as predictors of hearing aid acceptance. Clin Otolurngol (in press).

Accepted 15 December 1989

\section{Autonomic neuropathy after treatment with cisplatin, vinblastine, and bleomycin for germ cell cancer}

\author{
Steen Werner Hansen
}

Department of Oncology, Finsen Institute,

Rigshospitalet, DK 2100 Copenhagen, Denmark Steen Werner Hansen, $\mathrm{MD}$, clinical research assistant

Br.Med f 1990;300:511-2
Diseases and poisons that affect the peripheral nervous system can cause dysfunction of the autonomic nerves. ${ }^{\prime}$ Cytotoxic treatment with cisplatin or vinca alkaloids, or both, can have this complication.' Most patients with germ cell cancer treated with cisplatin and vinca alkaloids are cured, and thus knowledge of the prevalence and degree of autonomic neuropathy in these patients is important. I performed a study to investigate this.

\section{Patients, methods, and results}

All patients referred to this institute with metastatic germ cell cancer between March 1979 and December 1983 were treated with six courses of cisplatin, vinblastine, and bleomycin. Patients in whom a lasting complete remission occurred and who did not have

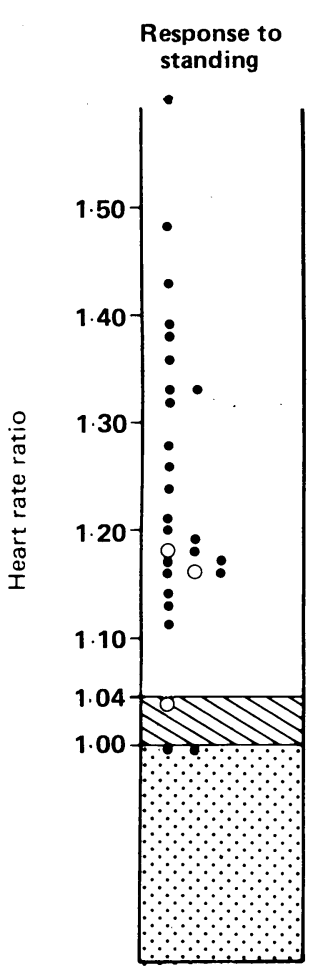

evidence of disease causing neuropathy were asked to participate in an examination of the functioning of their autonomic nerves. Informed consent was obtained from all patients. The heart rate response to Valsalva's manoeuvre, standing up, and deep breathing was used to evaluate function of the parasympathetic nerves, ${ }^{2}$ and function of the sympathetic nerves was assessed by measuring the postural changes in blood pressure. The results were analysed by using values recommended by Ewing and Clarke. ${ }^{2}$

Thirty four patients were eligible for the study, of whom six declined to participate. The 28 patients studied had a median age of 35 (range 19-55) years and had been followed up for a median of 83 (range 60-116) months. The only complaint related to autonomic dysfunction was impotence, which was found in three patients. Retroperitoneal lymph nodes were not dissected in any patient.

The figure shows the results of the three tests of functioning of the parasympathetic nerves. Minimal damage (one abnormal result) was found in eight patients; two of these patients, one of whom was impotent, yielded a borderline abnormal result in one of the two other tests. Two patients had two abnormal results, indicating definitive damage to the parasympathetic nerves, and one of these patients was also impotent. Eighteen patients showed no sign of dysfunction of the parasympathetic nerves, but in two of these the result of one test was borderline abnormal. Postural hypotension was not seen in any patient, although a borderline abnormal decrease in systolic pressure occurred in eight patients.

\section{Comment}

Most patients treated with cisplatin, vinblastine, and bleomycin have a peripheral sensory neuropathy of the "dying back" type affecting both large and small fibres. ${ }^{3}$ Conditions affecting small fibres are most likely to cause autonomic dysfunction, ' and it is therefore not surprising that we observed dysfunction of the parasympathetic nerves in 10 patients. Peripheral sensory neuropathy may also explain the impotence in two of the three patients who were affected. This is important, as most doctors believe that impotence is a psychological effect of the diagnosis and treatment of testicular cancer. Furthermore, the autonomic dysfunction may become disabling when these patients are aging as it is thought to play an important part in dysfunction of the bladder, postural hypotension, and thermoregulatory insufficiency in the elderly.

None of the patients we studied had postural hypotension, and this accords with the observation that postural hypotension is uncommon in "dying back" neuropathies that affect the large fibres of the long nerves. ${ }^{\prime}$ Cardiorespiratory arrests have occurred in patients with diabetes mellitus and autonomic dysfunction, often during or immediately after anaesthesia. ${ }^{+}$Sudden deaths that occur in patients treated with cisplatin, vinblastine, and bleomycin are believed to be caused by vascular toxicity ${ }^{5}$ but may in fact be caused by autonomic dysfunction. as ratio of heart rate $30 \mathrm{~s}$ after standing to that $15 \mathrm{~s}$ after standing), I'alsalva's manoeuvre (measured as of maximum heart rate to heart rate at rest), and deep breathing (measured as increase in heart rate).

Hatched areas indicate borderline abnormal values, stippled areas indicate abnormal values. $\mathrm{O}=$ Patients with impotence 
Autonomic dysfunction is a long term complication of treatment with cisplatin, vinblastine, and bleomycin and may explain the impotence that occurs in some patients. Presumably these young men are at risk during anaesthesia as cardiorespiratory arrests have occurred in patients with similar dysfunction.

1 McLeod JG, Tuck RR. Disorders of the autonomic nervous system: part 1 . Pathophysiology and clinical features. Ann Neurol 1987;21:419-30.
2 Ewing DJ, Clarke BF. Autonomic neuropathy: its diagnosis and prognosis. Clinical Endocrinology and Metabolism 1986;15:855-88.

3 Hansen SW, Helweg-Larsen S, Trojaborg W. Long-term neurotoxicity in patients treated with cisplatin, vinblastine, and bleomycin for metastatic patients treated with cisplatin, vinblastine,

4 Page MMcB, Watkins PJ. Cardiorespiratory arrest and diabetic autonomic neuropathy. Lancet 1978 ;i:14-6.

5 Samuels BL, Vogelzang NJ, Kennedy BJ. Severe vascular toxicity associated with vinblastine, bleomycin, and cisplatin chemotherapy. Cancer Chemother Pharmacol 1987;19:253-6.

(Accepted 9 November 1989)

\section{Association between living conditions in childhood and myocardial infarction}

\author{
Henrik Hasle
}

\begin{abstract}
Institute of Community
Health, Department of

Social Medicine,

University of Odense,

5000 Odense C, Denmark

Henrik Hasle, MD, research
\end{abstract}

fellow

Br Med J 1990;300:512-3 semiskilled workers.
Several studies have reported an association between cardiovascular diseases in adulthood and poor living conditions in childhood. ${ }^{12}$ I studied the association between living conditions in childhood and myocardial infarction in a well defined group of male unskilled and

\section{Subjects, methods, and results}

I conducted a nested case-control study based on information obtained in a case-control study designed to elucidate the factors giving rise to disability pensions for unskilled and semiskilled workers. ${ }^{3}$ Each consecutive male member of the Danish general workers' union who was granted a disability pension (pensioner) between 1 January 1984 and 1 March 1986 was included in the study. For each pensioner three union members matched for age and sex were recruited as controls. A self administered postal questionnaire was returned by $2602(73 \cdot 3 \%)$ of the study population ( $75 \cdot 2 \%$ of the pensioners and $72 \cdot 6 \%$ of the controls). Only subjects who had been union members for over 10 years and were aged 50-67 were studied - that is, 448 pensioners and 1225 controls. My study was concerned only with answers to the question "Have you ever had a myocardial infarction?" and to questions about living conditions in childhood.

Altogether 154 of the study population had had a myocardial infarction (88 pensioners and 66 controls). No significant difference in the age distribution of those who had and had not had a myocardial infarction was observed (mean age $58 \cdot 1$ and 57.9 respectively). The table shows the results obtained from the questions on living conditions in childhood. Odds ratios and $95 \%$ confidence intervals were calculated for each question regarding the most common answer among the men who had had a myocardial infarction. No significant differences were observed in the study group overall, but broken homes and urban residence were significantly associated with myocardial infarction in the control group.

No differences were observed in essential indications of poverty such as father's occupation, long term unemployment, and economic problems. Although not significant, the odds ratio for myocardial infarction among men with a short education was notably increased $(1 \cdot 95)$.

\section{Comment}

The study relied on a self reported history of myocardial infarction, which seems justified because heart disease is one of the chronic illnesses for which self reporting is fairly accurate. The study was based on questionnaires received from men who had survived a myocardial infarction. Such survivors may have different backgrounds from those of people who die, although it seems unlikely that living conditions in childhood influence the chance of survival.

The results could be biased by the high number of pensioners in the study. Separate analyses of the pensioners and controls did not show any systematic differences. A previous case-control study showed no association between living conditions in childhood and receipt of a disability pension. ${ }^{3}$

The study population was strikingly homogeneous in terms of education: $89 \cdot 7 \%$ had received seven years' education or less. It is difficult to find significant associations in such a homogeneous group, although there was a fairly strong tendency towards fewer cases of myocardial infarction among those with more than seven years' education.

The results are inconsistent with previous population based studies. ${ }^{12}$ Finding unfavourable living conditions in childhood in an area with a high mortality from cardiovascular diseases does not necessarity imply a causal relation. The highest infant mortality is found in poor areas that have remained poor throughout the century, ${ }^{4}$ and the incidence of cardiovascular diseases is highest among the lowest social class. ${ }^{5}$ The association of myocardial infarction with childhood conditions ${ }^{12}$ could be explained by confounding as low social class is associated with infant mortality, poverty in childhood, and cardiovascular diseases.

Living conditions in childhood may influence a person's career and lifestyle in adulthood and so be an

Living conditions experienced in childhood by men who had had myocardial infarction

\begin{tabular}{|c|c|c|c|c|c|c|c|c|c|}
\hline & \multicolumn{3}{|c|}{$\begin{array}{l}\text { Men who were receiving } \\
\text { disability pension } \\
(\mathrm{n}=88)\end{array}$} & \multicolumn{3}{|c|}{$\begin{array}{l}\text { Men who were not receiving } \\
\text { disability pension } \\
(n=66)\end{array}$} & \multicolumn{3}{|c|}{$\begin{array}{l}\text { Entire study group } \\
\qquad(n=154)\end{array}$} \\
\hline & No & $\begin{array}{l}\text { Odds } \\
\text { ratio }\end{array}$ & $\begin{array}{l}\text { 95\% Confidence } \\
\text { interval }\end{array}$ & No & $\begin{array}{l}\text { Odds } \\
\text { ratio }\end{array}$ & $\begin{array}{l}\text { 95\% Confidence } \\
\text { interval }\end{array}$ & No & $\begin{array}{l}\text { Odds } \\
\text { ratio }\end{array}$ & $\begin{array}{l}95 \% \text { Confidence } \\
\text { interval }\end{array}$ \\
\hline Father was an unskilled worker & 37 & $1 \cdot 24$ & 0.77 to 1.99 & 27 & $1 \cdot 07$ & 0.65 to $1 \cdot 77$ & 64 & $1 \cdot 13$ & 0.80 to 1.58 \\
\hline Did not grow up with both parents & 12 & 1.05 & 0.53 to 2.08 & 16. & 1.94 & 1.09 to 3.46 & 28 & $1 \cdot 38$ & 0.89 to $2 \cdot 12$ \\
\hline Father was unemployed for a long period & 15 & 0.95 & 0.51 to 1.76 & 16 & $1 \cdot 27$ & 0.71 to 2.27 & 31 & 1.04 & 0.69 to 1.57 \\
\hline Parents were sick & 26 & 1.54 & 0.92 to 2.59 & 14 & $0 \cdot 90$ & 0.49 to 1.64 & 40 & $1 \cdot 19$ & 0.82 to 1.74 \\
\hline Parents received disability pension & 22 & $1 \cdot 41$ & 0.81 to 2.43 & 10 & $0 \cdot 81$ & 0.32 to 2.04 & 32 & $1 \cdot 22$ & 0.81 to 1.84 \\
\hline Economic problems & 39 & $1 \cdot 30$ & 0.81 to 2.07 & 28 & 1.08 & 0.65 to 1.78 & 67 & $1 \cdot 16$ & 0.83 to 1.62 \\
\hline Urban residence & 27 & 1.05 & 0.63 to 1.74 & 27 & $1 \cdot 84$ & 1.11 to 3.03 & 54 & $1 \cdot 39$ & 0.98 to 1.98 \\
\hline$\leqslant 7$ Years of schooling & 83 & $2 \cdot 13$ & 0.83 to 5.46 & 62 & $1 \cdot 84$ & 0.67 to 5.07 & 145 & 1.95 & 0.99 to 3.85 \\
\hline
\end{tabular}

